\title{
LA CULTURA DEL TERRITORIOํㅗ DE JAVIER GARCÍA-BELLIDO
}

\author{
Isabel Rodríguez Chumillas \\ Profesora Titular de Análisis Geográfico Regional de la Facultad de Filosofía y Letras, \\ Departamento de Geografía \\ Universidad Autónoma de Madrid \\ Madrid, España
}

Remisión Artículo: 31-1-2007

Palabras Claves: Paisaje, Urbanismo de exclusión, Geografía Urbana, Visión estratégica territorial, Manifiesto por una nueva cultura del territorio.

\section{Desde la Geografía urbana territorial}

Entre los supuestos y posibilidades que caben dentro de esta referencia temática en la historiografía de Javier García-Bellido ${ }^{2}$ rescataremos a modo de ejemplo, para sentar las bases de una revisión más completa, tres obras de García-Bellido ${ }^{3}$ para examinar su contribución al pensamiento teórico que lleva tiempo empeñado en el papel protagonista de -que debe teneruna visión del territorio integradora de problemas y disciplinas. Al tiempo, este encargo de la revista ACE, desea en esta ocasión, enfatizar los "relatos de la experiencia". Son dos objetivos, en este caso, casi irreconciliables ${ }^{4}$. $Y$ es que el destino no ha permitido desarrollar una praxis significativa en esta visión geográfica compartida entre Javier García-Bellido y la autora de estas líneas. Sólo el empeño de rescatar expresamente algunas pequeñas experiencias ${ }^{5}$ me permitirá esbozar algún rastro del abanico crisol de experiencias que la vida y obra de Javier García-Bellido creó.

\footnotetext{
${ }^{1}$ En referencia explícita al Manifiesto por Una nueva cultura del territorio, decálogo de condiciones y principios para el impulso de los valores de sostenibilidad ambiental, la búsqueda de eficiencia económica y de equidad social, entre las metas más importantes que debe sostener el territorio.

2 Índice del propio número de ACE a cargo de Susana Ruiz.

${ }^{3}$ De entre los 18 títulos agrupados bajo el prisma urbano territorial de la visión geográfica de García-Bellido por Susana Ruiz, se revisan las convergencias y logros de la aportación de Javier García Bellido en las tres siguientes obras: (1982): "Políticas de planeamiento para la recuperación social del patrimonio cultural de la ciudad: Plan Especial para la totalidad del suelo urbano de Getafe", en Patrimonio Arquitectónico y Urbanístico, III Jornadas de Estudio sobre la provincia de Madrid, pp. 221-252, Madrid: Diputación de Madrid; (2002): "La cuestión rural: patología urbanística del espacio rústico", CYT-ET, XXXIV:132:277-323, verano y (2004): Y cuando se acabe el suelo del municipio,....¿qué hacer?", CYT-ET, XXXVI:139: 5-13, primavera.

${ }^{4}$ Que merecen ser explicitados por su aparente contradicción y su gran importancia para esta aportación.

${ }^{5}$ Experiencias que se abordan -en el epígrafe "Iconos geográficos del arquitecto"- por extraordinariamente expresivas de su visión territorial de vocación geográfica, y por los hilos de conexión que nacen de inquietudes y temas comunes. Es el caso del interés común por el estudio de la importancia de los grandes propietarios del suelo que se concretaba en estos últimos años por el suelo y las propiedades militares en España y que por limitaciones de espacio no se abordarán en este texto. Estas metas compartidas alimentaban -también en su faceta más lúdica y biológica de reuniones entorno a un plato de bacalao- actividades comunes de promoción y colaboración en la temática que llevó a la publicación de Brandis, D. -Canosa, E.-Mollá, M-Rodríguez, I.-Sáez, E. (2005): CyT-ET, 144: 391-417, dónde el referente común era el geógrafo Rafael Mas, colega y maestro, del equipo por él formado para el estudio de la propiedad militar en Madrid en torno al proyecto de investigación a su cargo.
} 


\section{Lenguaje común a través del territorio: el paisaje a examen.}

En la explicación de las transformaciones ligadas a la globalización, la perspectiva de las formas espaciales del análisis territorial es uno de los más apropiados convertidores para detectar el manejo que de los procesos cualitativos (sociales, económicos,..) se ha hecho por los grupos sociales. Esto es así porque en el territorio se han escrito las leyes de la organización social a lo largo del tiempo. En él se yuxtaponen e interaccionan, en el espacio, las preexistencias como fusión de naturaleza y cultura en sus distintos estadios tecnológicos. Todavía ni las acciones legislativas, ni las técnicas han comprendido su mutua integración (memoria natural e histórica), en el marco territorial ${ }^{6}$, y esto es lo que aborda Javier cuándo examina la cuestión rural e intenta explicar "el proceso imparable de destrucción global del frágil espacio rural en España por aplicación acumulativa y generalizada de decisiones basadas solamente en 'lógicas locales' "(García-Bellido, 2002, 277)?

Con la lectura histórica del lenguaje de la construcción del territorio que interpreta Menéndez (2005), básicamente coincidente con la visión-ideario de los geógrafos ${ }^{8}$, se leen las permanencias que lo han estructurado y estructuran, los signos de la perdurabilidad que le han ido dando permanencia. Esta es la búsqueda común ${ }^{9}$, que es compartida porque, en efecto, entendemos que un modo de hacerlo, de leer estas permanencias, es el lenguaje común de la construcción territorial en el que convergen ingenieros (Menéndez, 2005) ${ }^{10}$ y arquitectos, con el lenguaje de patrones (Méndez, 2006) ${ }^{11}$. Dice Javier que "exactamente esta constatación evidente es lo que exige y justifica las diversas escalas de análisis de los campos o regiones disciplinares de las respectivas ciencias que investigan la realidad y que se van acoplando unas dentro de otras, como las matrioscas rusas, transcurriendo (sólo referido a rangos espaciales) por los niveles crecientes donde la arquitectura (casa), el urbanismo (ciudad), la geografía (región), la ecología (ambiente) y la coranomía (globalidad)" (García-Bellido, 2002, 279). Son los hilos que dan coherencia al entendimiento del mundo, leyendo en el territorio sus paisajes construidos con el lenguaje atemporal de los patrones de las soluciones universales. Éstas, sometidas sucesivas veces a examen -tantas cómo soluciones encontradas- por el conjunto social coetáneo, han superado la prueba del devenir histórico, con un mayor o menor éxito que ha quedado expresado en los paisajes construidos.

\footnotetext{
${ }^{6}$ En definitiva es lo que Javier García-Bellido pone de manifiesto es las tres obras seleccionadas: "La cultura política de las formas democráticas elementales es esencialmente contradictoria cuando se trata de proteger los valores e intereses contemplados a escala global que, por definición, desbordan los concretos e inmediatos intereses individuales de las escalas locales decisorias" (García-Bellido, 2002, 319).

${ }^{7}$ Su conclusión son unas reflexiones finales bañadas por el pesimismo de un proceso inexorable, aunque dilatable, como reza textualmente (317).

${ }^{8}$ Recogidas genéricamente en el Manifiesto por una Nueva cultura del territorio dónde quedan integradas las más específicas de la línea metodológica de la morfología urbana (Vilagrasa 1991, Gómez, 1999, Rodríguez 2006).

${ }^{9} \mathrm{Y}$ base de la admiración de Javier García-Bellido por los trabajos de este autor.

${ }^{10}$ Menéndez (2005) propone conversar con un lenguaje común, integrador, para eliminar el procedimiento segregador con el que se responde a los procesos actuales dónde se busca disminuir costes urbanizando en más extensiones y contrarrestar sus efectos con la protección de cotos cerrados de naturaleza: catálogos de protección de paisajes naturales y humanos, los fuera de catálogo son espacios neutros desvalorizados (nada más lejos de la estrategia rehabilitadota sobre el territorio).

${ }^{11}$ Apoyándose en el lenguaje de patrones de Alexander formulado hace casi medio siglo. Méndez, E.- Rodríguez, I. (2006): Paisajes y arquitecturas de la exclusión, Madrid, Servicio de Publicaciones de la Universidad Autónoma de Madrid (en prensa).
} 
Dice Javier, después de revisar con gran detenimiento las leyes vigentes ${ }^{12}$ y ver los resquicios que "dejan abiertas para que el suelo rústico pueda ser mucho más extensivamente edificado, acercándose a su inexorable extinción..."(García-Bellido, 2002, 294), y pese a ello, apuesta por que la misión del intelectual está en adelantar ideas, prevenir, advertir y orientar la opinión política. (...) y en el tema del campo y su preservación creo que es un problema cultural y no sólo legal o disciplinar de aplicación rigurosa de las leyes (aunque también lo sea)" (320). La convicción de Javier: "Desde nuestra perspectiva geográfica nos basta reconocer que cuanto menor sea la escala desde la que se perciba un problema espacial, es decir, cuanto más nos alejemos de los intereses privados que gobiernan las decisiones aisladas de los individuos en el espacio geográfico, mayor y mejor será la percepción global de las interacciones y los fenómenos que éstos generan, alterando y transformando, a veces irreversiblemente, este territorio" (278-279), converge plenamente en el papel estratégico de la visión territorial . Así lo explicita cuándo se pregunta ¿cuando se acabe el suelo del municipio...qué hacer? ${ }^{13}$ : "Nuestro territorio es algo mucho más importante que ser un paciente soporte de las políticas urbanísticas (...). Por ello es un recurso estratégico de primera magnitud irrenunciable e innegociable" (García-Bellido, 2004, 5).

$Y$ es que el territorio, algunos de cuyos valores y rasgos son condensados en el Manifiesto por una nueva cultura del territorio ${ }^{14}$, es un bien no renovable, esencial y limitado ${ }^{15}$ cuyas características naturales y pervivencias en él de trazados, y sus formas provenientes del pasado, le confieren singularidad y valores de diversidad.

Los geógrafos a la cabeza, con otros analistas, y por las conclusiones que expresamos de Javier, podemos decir que todos convenimos por ello, que el territorio debe ser entendido como recurso, pero también como cultura, historia, memoria colectiva, referente identitario, bien público, espacio de solidaridad y legado.

Otros muchos principios básicos de esta visión y misión ${ }^{16}$ son compartidos por García-Bellido en estos tres representativos textos de este entendimiento del factor territorial, especialmente, es coincidente en el énfasis que se hace del planeamiento territorial cómo instrumento esencial de la actuación de los poderes públicos. El punto de encuentro es, en efecto, en palabras de Javier García-Bellido: "adoptar consensuadamente en provecho regional-colectivo", es decir "se precisa, por tanto, un planeamiento regional activo, propositito a niveles municipales, no solo para que reserven o protejan los espacios y usos supramunicipales, sino para activar los procesos decisionales urbanos internos de los municipios en una gestión verdaderamente compartida" (10). No duda en robustecer la crítica directa a las prácticas urbanísticas municipales en sus últimas palabras: "Dejemos, pues, la pequeña escala y las lógicas

\footnotetext{
${ }^{12}$ Escruta el entramado jurídico que habilita las segregaciones rústicas de la propiedad en unidades mínimas de cultivo de la legislación agraria. (García Bellido, 2002, 278).

${ }^{13}$ En el Editorial del número 139, del 2004.

${ }^{14}$ Ver Manifiesto por una nueva cultura del territorio en la pagina web de la Asociación de Geógrafos españoles, http://age.ieg.csic.es/.

${ }^{15}$ Como expresa la primera convicción del citado Manifiesto.

${ }^{16}$ Cómo el $4^{\circ}$ enunciado del decálogo del Manifiesto que dice: "un territorio bien gestionado constituye un activo económico de primer orden. La gestión sostenible del territorio es ciertamente una obligación social y ambiental, pero resulta también un apremiante imperativo económico".
} 
apremiantes y abrumadoras de lo local para sumergirnos en las lógicas solidarias y generosas de lo supramunicipal..." (12) ${ }^{17}$, y al tiempo, cómo se observa, abogar por ser, cómo dice el Manifiesto: "sobre las Comunidades Autónomas -sobre las que- recae la gran responsabilidad de demostrar una mayor voluntad política de ordenar su territorio superando la situación creada casi exclusiva del planeamiento urbanístico"18.

Y por supuesto, la convergencia está presente en la acotación de la cuestión rural ${ }^{19}$ propiamente, quizás más que otras cuestiones, que sólo en la práctica y gestión de territorios concretos podría alcanzar -al menos por nuestra parte- esa visión de consenso, sobre la defensa del espacio abierto, como matriz territorial básica. Es hoy una prioridad que debe ser perseguida adecuadamente, pero son muchos los ejemplos que ponen de manifiesto que no priorizar los perjuicios sociales que resultan de una aplicación genérica de "la defensa del espacio abierto" en la actual estructura territorial, negando la vocación urbana de algunos territorios, es volver a caer en los mismos errores de las bondades de una buena proyección de futuro ajena a la cotidianidad de la vida en los desarticulados territorios urbanizados ${ }^{20}$.

\section{Explorando los paisajes de la exclusión}

Las permanencias que reestructuran continuamente el territorio también han provocado una clarificación y simplificación del espacio inicial: la homogeneidad vacía del espacio se convierte en territorio, lo cualitativamente diferenciado ${ }^{21}$. El territorio muestra que el espacio y el tiempo tienen significados cambiantes que se explican en sus diferencias y se expresan en sus paisajes. Pero también, en efecto, progresivamente despojan al territorio de sus

\footnotetext{
17 En el principio quinto del decálogo de la cultura del territorio se señala, en efecto, que "el conjunto de administraciones competentes deben propiciar pues una revalorización del planeamiento territorial y general, suprimiendo la utilización espuria de otros instrumentos de menor alcance espacial pero con alta incidencia real, cuya aplicación abusiva ha tenido como consecuencia la urbanización masiva, desordenada e inadecuada de suelo rústico". Pero sobre todo, se incide también en esta unidireccional vía de la política urbanística de los municipios y el territorio cuando señala que "ante esta deriva, hay que defender planes municipales de ordenación que atribuyan valores positivos a todas y cada una de las partes del término municipal, basando el crecimiento urbano en criterios ecológicos y sociales, más allá de la simple consideración de la oportunidad económica o de ocasionales negocios particulares inmediatos". Manifiesto por una nueva cultura del territorio en la página web de la Asociación de Geógrafos españoles, http://age.ieg.csic.es/.
}

${ }^{18}$ Manifiesto por una nueva cultura del territorio en la página web de la Asociación de Geógrafos españoles, http://age.ieg.csic.es/.

${ }^{19}$ En particular, dice el sexto enunciado del decálogo del Manifiesto por una Nueva Cultura del territorio que "debe abandonarse la concepción del suelo rústico como un espacio residual, perennemente pendiente de urbanización futura y comprender que la permanencia de suelos rústicos destinados a las prácticas agrarias se hace imprescindible por razones ambientales y ecológicas, incluso en los contextos espaciales de las mayores ciudades y aglomeraciones urbanas".

${ }^{20}$ Un buen exponente del ideario y la confianza en el planeamiento es precisamente el estudio que Javier realiza del planeamiento municipal de Getafe en el contexto de las políticas de planeamiento regional. Sobre todo para demostrar, pormenorizadamente, la distancia insalvable entre las propuestas de recuperación social del patrimonio cultural de la ciudad y la práctica urbanística coetánea (García-Bellido, 1982).

${ }^{21}$ Este autor ha expresado que los procesos de innovación inherentes al devenir histórico, constituye la consecuencia más acabada de la propuesta consensuada sobre el fracaso del entendimiento de una ordenación y planificación territorial cerrada, en la que se quiere determinar el futuro de acuerdo a esquemas simplificados. La búsqueda del plano ideal de la superficie plana, o de otras técnicas y diseños "simplificadores-operativos", ajustan éste y otros elementos determinantes de estructuras primarias a patrones de regularidades básicas. (Menéndez 2005, 333-4). 
condicionamientos de lugar y lo transforman en espacio abstracto ${ }^{22}$, sólo simple extensión dónde se anula el sentido del tiempo. De hecho, el paisaje sometido a examen en tiempos de la globalización, supone la inserción contextual de lo urbano en territorios en metamorfosis de entornos dominantemente urbanizados, y eso requiere, necesariamente, un replanteamiento con términos nuevos de análisis ${ }^{23}$, pues como dice Javier García Bellido, "al ser ya todo un territorio urbanizado", los parques regionales y espacios naturales funcionan como grandes espacios libres o zonas verdes de recreo" ${ }^{24}$. Aún hoy es excepcional la visión de comprender y explicar sus consecuencias y proponer alternativas a partir del proceso histórico de construcción territorial descifrando su lenguaje, que no puede significar hoy sólo seguir describiendo y clasificando. $Y$ ahí es dónde es fácil asignarle a Javier García-Bellido, por la experiencia como "emisaria" -que él mismo otorgó a la autora de estas palabras ${ }^{25}$-, su naturaleza exploradora ${ }^{26}$, icono geográfico del más primitivo de los imaginarios 'humboltianos' de la disciplina. Porque, los paisajes en construcción de este territorio urbanizado muestran que no sólo es ya cotidiana la fractura espacial sino que es la fórmula globalmente aceptada e incesantemente aplicada en la intervención en el territorio.

El encargo de Javier García Bellido, a la larga, ha conducido al análisis del límite como unidad de medida de las relaciones y procesos espaciales actuales y a reflexionar sobre la extrapolación del límite como dispositivo propulsor de la urbanización del territorio, que ha disparado el ritmo e intensidad de la continua segregación que va escindiendo sucesivos espacios diferenciados. Entre las permanencias que reestructuran continuamente el territorio, la idea del límite -se expresa en un control del territorio-, ha tomado diversas materializaciones, sobre todo, regularizaciones que han intentando progresivamente reducir la complejidad original del medio natural extendiendo lo urbano en una continua estratificación de acciones sucesivas, que hoy multiplican las barreras que segregan el territorio reafirmando su fuerza como facilitador de la expansión difusa y la reorganización espacial. Nos ha llevado a considerar que para explicar los paisajes urbanos en la globalización hay que clarificar las reglas de los juegos en curso sobre el encierro y los discursos del otro ${ }^{27}$ que ya han desplegando diversas estrategias anticipando las defensas (encerrarse) para prevenir las

\footnotetext{
${ }^{22}$ Un método, como el cartesiano, que hace tabla rasa de cualquier precedencia histórica o cultural, en el que hay un rechazo de todo contexto espacial, social o temporal incesantemente aplicadazo como método de ordenación territorial a distintas escalas y en distintas latitudes a lo largo del tiempo.

${ }^{23}$ Las clasificaciones y abordajes del paisaje excluyen, explícitamente, la disección y análisis de los paisajes urbanos que, no obstante, son incorporados cómo elementos determinantes en la dominancia natural y/o rural de las unidades de paisaje integrado que, paradójicamente, recomponen el conjunto del territorio a inventariar. Véase Gómez (1999): Los paisajes de Madrid. Paisajes naturales y rurales, Madrid, Fundación Caja Madrid.

${ }^{24}$ García-Bellido, J. 2004, 8.

${ }^{25}$ Realizar una balance del tema y los trabajos presentados en el Coloquio Ciudades cerradas países abiertos organizado por Cabrales, L. F. en Guadalajara, México en julio de 2002. Ver CyT-ET, 132, 2002 y Cabrales, L. F. (2002): Ciudades cerradas, países abiertos, Universidad de Guadalajara.

${ }^{26}$ Se le reconoce un gran afán y lucidez en favorecer los caminos y recursos para abordar y promover el estudio de un tema de la máxima importancia, al que dedicó un número monográfico en la revista Ciudad y Territorio a finales de 2002 dedicado al urbanismo de la exclusión.

27 También se puede enunciar esta segunda hipótesis considerando que, precisamente, la percepción del carácter limitado del planeta, ha determinado la exacerbación de la separación para garantizar lo privado. Así, el muro evidencia la yuxtaposición entre el adentro y el afuera, precisamente, porque no lo hay, requiere explicitarse, materializarse, constituir el punto de concreción para naturalizar el límite y que se familiarice la sociedad con la incomunicación, o con la diferencia, la distinción, lo otro.
} 
destrucciones (identificación de enemigos ${ }^{28}$ ) y, siempre, mantenerse expectante a la creatividad, al azar y a la incertidumbre ${ }^{29}$. Es decir, los discursos y las prácticas del urbanismo cerrado, cómo otros instrumentos técnico-conceptuales, anulan el sentido del tiempo, de la distancia física y del pasado, esto es, son soluciones -configuran paisajes nuevos- creadas para un tiempo especializado ajeno a la experiencia. El límite ha permitido la introducción de nuevos parámetros de trocear el territorio para su uso, ahora la urbanización del territorio se organiza con el patrón del límite ${ }^{30}$. La unidad de medida en la escala de la ciudad difusa contemporánea es el límite. Por lo pronto, desmenuzar un sistema urbano territorial cómo el actual requiere manejar un método detallado de análisis del territorio y sus paisajes. Hay un saber hacer, un lenguaje de patrones ya escrito que hay que identificar en cada territorio y que se impone en la domesticación progresiva de los territorios en su devenir histórico. Por eso la necesaria redefinición de categorías de análisis y la evidencia de nuevos paisajes urbanos en construcción.

\footnotetext{
${ }^{28}$ La inmigración, la pobreza, el terrorismo, la violencia, el miedo, entre los más destacados.

${ }^{29}$ Dice Bauman que "la nueva preocupación por los temas medioambientales debe su popularidad a la extendida percepción de la existencia de una conexión entre el mal uso predatorio de los recursos comunes del planeta y la amenaza que ello podría suponer para el desarrollo fluido de las actividades egocéntricas de la vida líquida" Bauman, Z. (2006): Vida líquida, Barcelona, Paidós, 201 Págs., pp. 21.

${ }^{30}$ La exacerbación del límite en las sociedades actuales con la tendencia al encerramiento y la consecuente fragmentación del territorio, es el cuello de botella que puede estrangularla porque ambos factores han roto la continuidad de las redes multiplicando los límites y espacios que están despiezados.
} 